\title{
PENGARUH MOTIVASI KERJA, GAYA KEPEMIMPINAN DAN PENGALAMAN KERJA TERHADAP KINERJA KARYAWAN PT ELKAU
}

\author{
Sukri \\ Program Studi Magister Manajemen Universitas Tarumanagara \\ ahianrain@yahoo.co.id \\ Mukti Rahardjo \\ Program Studi Magister Manajemen Universitas Tarumanagara
}

Masuk : 24-11-2019, revisi : 19-12-2019 diterima untuk diterbitkan : 19-12-2019

\begin{abstract}
This study aims to analyze and prove work, work experience and leadership styles on employee work simultaneously or partially. This study used a survey using a questionnaire to 96 respondents, PT ELKAU staff. Sample selection is based on random sampling everywhere Every participant has the same opportunity to take samples. The results of this study prove that work motivation, work experience and leadership styles simultaneously influence employee performance. Partially, work experience increases performance with a significant level of 0,000 , work motivation while positive performance on performance is significant level of 0.017 and leadership style increases positive performance on work performance with a significant level of 0,000 . Further research is expected to add other factors that can improve job performance.
\end{abstract}

Keywords : work motivation, work experience leadership style, and employee performance

\section{Latar Belakang}

Perkembangan perekonomian dunia yang semakin kompetitif termasuk perkembangan perekonomian di Indonesia menyebabkan perubahan regulasi yang secara otomatis menuntut perusahaan agar ikut serta dalam penyejahteraan baik dalam lingkup eksternal dan internal perusahaan agar perusahaan dapat bertahan. Oleh sebab itu banyak sekali perusahaan yang berusaha untuk dapat bersaing dengan kompetitor di dalam industri bisnis yang dijalankannya dengan cara bagaimana suatu perusahaan dapat terus berjalan tidak hanya pada jangka pendek saja melainkan untuk jangka panjang atau dengan kata lain perusahaan harus tetap menjaga stabilitas perusahaan. Ditambah lagi dengan adanya Globalisasi yang sudah terasa dampaknya di Indonesia. Terkait hal tersebut tentu memiliki pengaruh terhadap tenaga kerja pada perusahaan-perusahaan yang ikut serta berperan dalam Globalisasi secara langsung maupun tidak langsung. Hal tersebut tentu menjadi perhatian penting baik dari sisi perusahaan dan tenaga kerja untuk bisa meningkatkan kinerja baik dari sisi profit perusahaan dan lainnya. Hal ini tentu didukung oleh adanya tenaga kerja terdidik yang memiliki kecakapan tertentu di bidangnya. Banyaknya pesaing yang masuk ke indonesia berimbas kepada perusahaaan kecil maupun besar yang menyebabkan tidak dapat bersaing dan berujung pada gulung tikar. Sebut saja salah satu contoh perusahaan skala besar yang pernah mendominasi dalam pasar elektronik yang telah resmi menutup kegiatan usahanya di Indonesia tahun 2016 yang dikutip di Sindonews.com yaitu PT Toshiba. barang di dalam negeri tidak dapat bersaing dari produk asal Negeri Tirai Bambu. Konfederasi Serikat Pekerja Indonesia (KSPI) mengungkapkan, membanjirnya produk elektronik China menjadi salah satu penyebab perusahaan Jepang, Toshiba menutup pabrik di Indonesia. Penjualan mereka menurun akibat perang harga, yang berujung pada penurunan produksi dan pemutusan hubungan kerja (PHK).

Dengan adanya kasus ini dapat menjadi pembelajaran bagi perusahaan-perusahaan lain untuk bagaimana caranya agar perusahaan tetap survive dan going concern. Salah satunya 
adalah dari sisi motivasi kerja dari seorang karyawan itu sendiri akan sangat menjadi faktor pendorong bagaimana karyawan tersebut dapat bekerja. Hal tersebut bisa disebabkan dari internal maupun eksternal seorang individu tersebut, banyak juga orang-orang termotivasi hanya pada tujuan akhir yaitu penghasilan saja, disinilah banyak orang salah menilai bahwa kerja hanya untuk uang saja. Hal ini yang menyebabkan pengalaman sesorang tidak dapat maksimal baik dari penerapan maupun yang akan didapatkan. Permasalahan yang kerap terjadi adalah pada gaya kepemimpinan. Perilaku pemimpin memiliki pengaruh yang signifikan terhadap sikap, perilaku dan kinerja pegawai. Efektivitas pemimpin dipengaruhi oleh karakteristik bawahannya dan tekait dalam proses komunikasi yang terjadi antara pemimpin dan bawahanya. Ketidakberhasilan pemimpin dikarena pemimimpin tidak mampu menggerakan dan memuaskan karyawan pada suatu pekerjaan dan lingkungan tertentu. Kemudian yang harus diperhatikan perusahaan adalah pengalaman dari seorang karyawan bekerja dalam sebuah perusahaan dengan posisi yang telah ditentukan. Porsi yang sudah diberikan berdasarkan tanggung jawab, hak, dan kewajiban seharusnya sesuai dengan pengalaman yang dimiliki melihat dari risiko yang ada pada setiap tanggung jawab tersebut. Karena dengan adanya pengalaman dengan tingkat kompleksitas yang lebih banyak tentu akan banyak membantu dalam pemecahan masalah yang ada dalam tanggung jawab yang dimiliki.

\section{Tujuan Penelitian}

Tujuan yang ingin dicapai dalam penelitian ini adalah sebagai berikut.

1. Untuk mengetahui pengaruh motivasi kerja, gaya kepemimpinan dan pengalaman kerja terhadap kinerja karyawan.

2. Untuk mengetahui dan menanalisis keterkaitan motivasi kerja terhadap kinerja karyawan.

3. Untuk mengetahui dan menanalisis keterkaitan gaya kepemimpinan terhadap kinerja karyawan.

4. Untuk mengetahui dan menanalisis keterkaitan pengalaman kerja terhadap kinerja karyawan.

\section{TELAAH KEPUSTAKAAN}

Menurut Robert dan Vijay Govindarajan (2013, p54-56), dari sudut pandang motivasi, teori maslow mengatakan bahwa meskipun tidak pernah ada kebutuhan yang pernah dipenuhi secara lengkap, suatu kebutuhan yang pernah terpenuhi secara substansial tidak lagi menjadi motivasi. Maslow menjelaskan dalam suatu hierarki lima kebutuhan dasar manusia dari tingkatan dasar sampai dengan tingkatan tertinggi. Secara lebih rinci kelima dasar kebutuhan manusia tersebut membentuk suatu hierarki kebutuhan sebagai berikut: Kebutuhan Fisiologis, Kebutuhan Keamanan, Kebutuhan Sosial, Kebutuhan Penghargaan, dan Kebutuhan Aktualisasi Diri.

George R. Terry (2003), mengatakan bahwa kepemimpinan adalah suatu hubungan antara seseorang dengan orang lain, pemimpin yang mampu mempengaruhi orang lain agar bersedia bekerja bersama-sama dalam tugas yang berkaitan untuk mencapai tujuan yang diinginkan.

Menurut Noe et al (2014, p279) Job Experiences is the combination of relationships, problems, demands, tasks, and employee's jobs. To be successful in their jobs, employees must stretch their skills-that is, they are forced to learn new skills, apply their skills and knowledge in a new way, and master new experiences.

Menurut Springer (2011) (sebagaimana dikutip Jamal, 2007), Suggests job performance is a function that an individual can successfully perform within framework of normal constraints and available resources. There are eight general factors of job performance, which includes: Job specific proficiency, Non-job specific task proficiency, Written and oral 
communication, Demonstrating effort, Maintaining personal discipline, Maintaining peer and team performance, Supervision / leadership, dan Management / administration.

Menurut Sekaran (2011, p135) Hipotesis bisa didefinisikan sebagai hubungan yang diperkirakan secara logis di antara dua atau lebih variabel yang diungkapkan dalam bentuk pernyataan yang dapat diuji. maka dapat dirumuskan hipotesis sebagai berikut:

$\mathrm{Ha}^{1}$ : Pengalaman Kerja, Motivasi Kerja, dan Gaya Kepemimpinan berpengaruh terhadap Kinerja Karyawan.

$\mathrm{Ha}^{2}$ : Motivasi Kerja berpengaruh terhadap Kinerja Karyawan.

$\mathrm{Ha}^{3}$ : Gaya Kepemimpinan berpengaruh terhadap Kinerja Karyawan.

$\mathrm{Ha}^{4}$ : Pengalaman Kerja berpengaruh terhadap Kinerja Karyawan.

\section{METODOLOGI PENELITIAN}

Menurut Narbuko dan Achmadi (2010, p44) penelitian deskriptif yaitu penelitian yang berusaha untuk menuturkan pemecahan masalah yang ada sekarang berdasarkan data-data, jadi ia juga menyajikan data, menganalisis, dan menginterpretasi. Penelitian mengenai pengaruh komuniaksi verbal dan non verbal terhadap kinerj karyawan PT ELKAU yang berdomisi di Jakarta Pusat. PT ELKAU berdiri tahun 2008 merupakan perusahaan yang bergerak di bidang perkebunan kelapa sawit yang memiliki 2 Representative Office, 5 Estates dan 1 Mill yang tersebar di Kalimantan Timur. Teknik penentuan sampel dalam penelitian ini menggunakan teknik penarikan sampel secara acak sederhana (simple random sampling).

Metode pengujian Uji Validitas \& Reliabilitas, Uji validitas merupakan uji instrumen data untuk mengetahui seberapa cermat suatu item dalam mengukur apa yang ingin diukur. Jika nilai positif dan $r$ hitung $\geq r$ table, maka item dapat dinyatakan valid, jika $r$ hitung $<r$ table maka item dinyatakan tidak valid (Priyatno 2014, p51). Uji reliabilitas digunakan untuk mengetahui keajegan atau konsistensi alat ukur yang biasanya menggunakan kuesioner. Untuk menentukan apakah instrument reliabel atau tidak menggunakan batasan 0,6. Menurut Sekaran (1992), reliabilitas kurang dari 0,6 adalah kurang baik, sedangkan 0,7 dapat diterima dan diatas 0,8 adalah baik (Priyatno 2014, p64).

Metode pengujian Uji Asumsi Klasik, Uji normalitas pada model grafik P-P Plot diketahui bahwa titik-titik menyebar sekitar garis dan mengikuti garis diagonal, maka nilai residual tersebut terdistribusi normal. Pengujian menggunakan tingkat signifikansi 0,05 dengan uji 2 sisi. Uji Simultan \& Parsial, Pengujian menggunakan tingkat signifikansi 0,05.

\section{ANALISIS DAN BAHASAN TEMUAN}

Analisis deskriptif jawaban responden ini dimaksudkan untuk menginterpretasikan distribusi frekuensi jawaban responden atas tiap pernyataan dari kuesioner, untuk mendeskripsikan hasil variable pengalaman kerja, motivasi kerja, gaya kepemimpinan dan kinerja karyawan yaitu berdasarkan jawaban responden pasa kuesioner yang telah disebarkan. Kuesioner yang disebarkan pada 87 responden terdiri dari 31 butir pernyataan.

\section{HASIL UJI VALIDITAS PENGALAMAN KERJA}

Item-Total Statistics

\begin{tabular}{|l|r|r|r|r|}
\hline & $\begin{array}{r}\text { Scale Mean if } \\
\text { Item Deleted }\end{array}$ & $\begin{array}{r}\text { Scale Variance } \\
\text { if Item Deleted }\end{array}$ & $\begin{array}{r}\text { Corrected Item- } \\
\text { Total Correlation }\end{array}$ & $\begin{array}{r}\text { Cronbach's Alpha } \\
\text { if Item Deleted }\end{array}$ \\
\hline X1 & 13.7471 & 2.121 & .463 & .555 \\
\hline X2 & 13.5402 & 2.484 & .319 & .622 \\
\hline X3 & 13.6897 & 2.263 & .441 & .569 \\
\hline X4 & 13.7931 & 2.236 & .283 & .656 \\
\hline X5 & 13.7356 & 2.150 & .503 & .538 \\
\hline
\end{tabular}


HASIL UJI VALIDITAS MOTIVASI KERJA

\begin{tabular}{|l|r|r|r|r|}
\hline & $\begin{array}{c}\text { Scale Mean if } \\
\text { Item Deleted }\end{array}$ & $\begin{array}{c}\text { Scale Variance } \\
\text { if Item Deleted }\end{array}$ & $\begin{array}{c}\text { Corrected Item- } \\
\text { Total Correlation }\end{array}$ & $\begin{array}{c}\text { Cronbach's Alpha } \\
\text { if Item Deleted }\end{array}$ \\
\hline $\mathrm{X} 6$ & 27.2529 & 6.819 & .659 & .749 \\
\hline $\mathrm{X} 7$ & 27.2069 & 7.143 & .591 & .760 \\
\hline $\mathrm{X} 8$ & 27.3218 & 7.174 & .483 & .773 \\
\hline $\mathrm{X} 9$ & 27.2299 & 7.435 & .420 & .782 \\
\hline $\mathrm{X} 10$ & 27.2874 & 7.486 & .465 & .776 \\
\hline $\mathrm{X} 11$ & 27.3563 & 6.906 & .660 & .750 \\
\hline $\mathrm{X} 12$ & 27.2644 & 7.499 & .426 & .781 \\
\hline $\mathrm{X} 13$ & 27.2644 & 7.290 & .507 & .770 \\
\hline $\mathrm{X} 14$ & 27.3333 & 7.783 & .217 & .815 \\
\hline
\end{tabular}

HASIL UJI VALIDITAS GAYA KEPEMIMPINAN

\begin{tabular}{|l|r|r|r|r|}
\hline & $\begin{array}{c}\text { Scale Mean if } \\
\text { Item Deleted }\end{array}$ & $\begin{array}{c}\text { Scale Variance } \\
\text { if Item Deleted }\end{array}$ & $\begin{array}{c}\text { Corrected Item- } \\
\text { Total Correlation }\end{array}$ & $\begin{array}{c}\text { Cronbach's Alpha } \\
\text { if Item Deleted }\end{array}$ \\
\hline X15 & 19.8966 & 4.931 & .329 & .707 \\
\hline X16 & 19.7586 & 4.395 & .587 & .651 \\
\hline X17 & 19.7586 & 4.813 & .401 & .693 \\
\hline X18 & 19.7701 & 4.807 & .379 & .697 \\
\hline X19 & 19.6207 & 4.657 & .453 & .681 \\
\hline X20 & 19.9310 & 4.042 & .456 & .684 \\
\hline X21 & 19.9540 & 4.091 & .449 & .683 \\
\hline
\end{tabular}

\section{HASIL UJI VALIDITAS KINERJA KARYAWAN}

\begin{tabular}{|l|r|r|r|r|}
\hline & $\begin{array}{c}\text { Scale Mean if } \\
\text { Item Deleted }\end{array}$ & $\begin{array}{c}\text { Scale Variance } \\
\text { if Item Deleted }\end{array}$ & $\begin{array}{c}\text { Corrected Item- } \\
\text { Total Correlation }\end{array}$ & $\begin{array}{c}\text { Cronbach's Alpha } \\
\text { if Item Deleted }\end{array}$ \\
\hline Y1 & 30.4713 & 8.275 & .408 & .758 \\
\hline Y2 & 30.7126 & 8.161 & .311 & .775 \\
\hline Y3 & 30.8046 & 8.903 & .219 & .779 \\
\hline Y4 & 30.7011 & 7.910 & .568 & .738 \\
\hline Y5 & 30.6552 & 7.624 & .595 & .732 \\
\hline Y6 & 30.7011 & 8.049 & .373 & .742 \\
\hline Y7 & 30.6552 & 7.949 & .535 & .733 \\
\hline Y8 & 30.4943 & 7.741 & .602 & .774 \\
\hline Y9 & 30.7126 & 8.649 & .276 & .737 \\
\hline Y10 & 30.5057 & 7.834 & .565 & .74 \\
\hline
\end{tabular}

Dari hasil output SPSS untuk uji validitas yaitu R table dicari signifkansi 0,05 dengan uji 2 sisi dan $\mathrm{N}$ adalah 87, maka didapat nilai $\mathrm{r}$ table adalah 0,220. Dari output menunjukkan bahwa r hitung semua item lebih dari 0,220. Dapat disimpulkan bahwa semua pernyataan pada variabel independen dan dependen adalah valid.

HASIL UJI RELIABILITAS

\begin{tabular}{|c|c|c|}
\hline Variabel & Cronbach's Alpha & N of Items \\
\hline Pengalaman Kerja &, 642 & 5 \\
\hline Motivasi Kerja &, 793 & 9 \\
\hline Gaya kepemimpinan &, 718 & 7 \\
\hline Kinerja Karyawan &, 773 & 10 \\
\hline
\end{tabular}


Berdasarkan hasil dari analisis reliabilitas dengan teknik Cronbach Alpha, dapat diketahui nilai Cronbach Alpha adalah nilai lebih dari 0,6, maka instrument kuesioner dinyatakan reliabel.

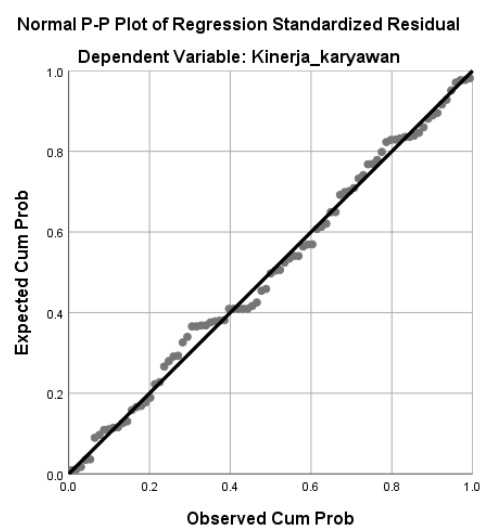

Gambar 4.1 Grafik Normal P-P Plot of Regression Standardized Residual

Dari grafik normal P-P Plot pada gambar 4.1 dapat disimpulkan dari grafik P-P Plot diketahui bahwa titik-titik menyebar sekitar garis dan mengikuti garis diagonal, maka nilai residual tersebut terdistribusi normal.

\section{HASIL UJI MULTIKOLINEARITAS}

\begin{tabular}{|ll|r|r|}
\hline \multirow{2}{*}{ Model } & \multicolumn{2}{|c|}{ Collinearity Statistics } \\
\cline { 3 - 4 } & (Constant) & \multicolumn{1}{c|}{ Tolerance } \\
\hline 1 & Pengalaman Kerja &, 540 & 1,850 \\
& Motivasi Kerja &, 588 & 1,700 \\
& Gaya kepemimpinan &, 896 & 1,116 \\
\hline
\end{tabular}

Berdasarkan table 4.6 diatas dapat dilihat bahwa angka tolerance dari variable pengalaman kerja, motivasi kerja, dan gaya kepemimpinan mempunyai nilai lebih dari 0,10 dan VIF kurang dari 10, maka dapat disimpulkan bahwa tidak terjadi multikolinearitas antar variable bebas.

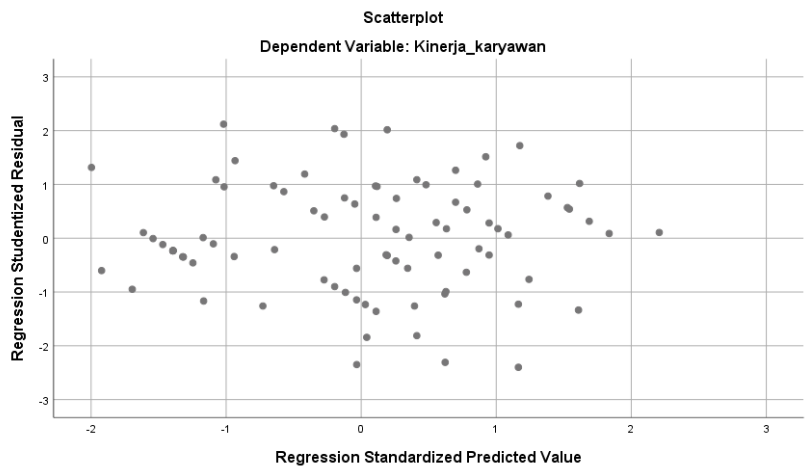

Gambar 4.2 Grafik Scatterplot

Dari output di atasa dapat diketahui bahwa titik-titik tidak membentuk pola yang jelas, dan titik-titik menyebar diatas dan dibawah angka 0 pada sumbu Y. Jadi dapat disimpulkan bahwa tidak terjadi masalah heteroskedastisitas pada model regresi. 
HASIL UJI PERSAMAAN REGRESI LINIER BERGANDA

\begin{tabular}{|ll|r|r|}
\hline \multirow{2}{*}{ Model } & \multicolumn{2}{|c|}{ Unstandardized Coefficients } \\
\cline { 3 - 4 } & \multicolumn{1}{|c|}{ B } & \multicolumn{1}{c|}{ Std. Error } \\
\hline 1 & (Constant) & 2.121 & 2.509 \\
& Pengalaman Kerja & .988 & .142 \\
& Motivasi Kerja & .198 & .082 \\
& Gaya kepemimpinan & .386 & .082 \\
\hline
\end{tabular}

Nilai yang didapatkan dari hasil output SPSS pada tabel 4.43 kemudian dimasukkan ke dalam persamaan linier berganda sebagai berikut:

$$
\mathrm{Y}=2.121+0,988 \mathrm{X} 1+0,198 \mathrm{X} 2+0,368 \mathrm{X} 3
$$

HASIL UJI F

\begin{tabular}{|c|c|c|c|c|c|}
\hline Model & Sum of Squares & Df & $\begin{array}{c}\text { Mean } \\
\text { Square }\end{array}$ & $\mathrm{F}$ & Sig. \\
\hline Regression & 589,253 & 3 & 198,41 & 60,064 &, $000^{\mathrm{b}}$ \\
\hline
\end{tabular}

Berdasarkan hasil output SPSS pada tabel 4.8, diperoleh F hitung sebesar 60,064 dan nilai signifikansi sebesar 0,000. Sedangkan $F$ tabel dengan df $1=3$ dan df $2(87-3-1)=80$, hasil yang diperoleh untuk F tabel sebesar 2,71. Sehingga dapat disimpulkan bahwa F hitung $>\mathrm{F}$ tabel $(60,064>2,71)$ dan signifikansi $<0,05(0,000<0,05)$, maka Ho ditolak sehingga dapat dikatakan bahwa Pengalaman Kerja, Motivasi Kerja, dan Gaya Kepemimpinan secara bersama-sama berpengaruh terhadap Kinerja Karyawan.

\section{HASIL UJI T}

\begin{tabular}{|ll|r|r|}
\hline \multicolumn{2}{|c|}{ Model } & \multicolumn{1}{c|}{$\mathrm{T}$} & \multicolumn{1}{c|}{ Sig. } \\
\hline $1 \quad$ (Constant) &, 846 &, 400 \\
& Pengalaman Kerja & 6,964 &, 000 \\
& Motivasi Kerja & 2,431 &, 017 \\
& Gaya & 4,736 &, 000 \\
& kepemimpinan & & \\
\end{tabular}

Dari tabel 4.45 hasil uji t didapatkan hasil t hitung yang kemudian dibandingkan dengan $\mathrm{t}$ tabel, $\mathrm{t}$ tabel statistik pada signifikansi $0,05 / 2=0,025$ dengan derajat kebebasan df (87-3-1) $=80$, hasil yang diperoleh untuk t tabel sebesar 1,989. untuk hasil kesimpulan secara parsial sebagai berikut:

a. Nilai t hitung Pengalaman Kerja sebesar 6,964 dengan signifikansi 0,000. Jadi, nilai t hitung > t tabel $(6,964>1,989)$ dan signifikansi $<0,05(0,000<0,05)$ maka Ho ditolak.

b. Nilai t hitung Motivasi Kerja sebesar 2,431 dengan signifikansi 0,017. Jadi, nilai thitung $>$ t tabel $(2,431>1,989)$ dan signifikansi < $0,05(0,017<0,05)$ maka Ho ditolak.

c. Nilai Gaya Kepemimpinan sebesar 4,736 dengan signifikansi 0,000. Jadi, nilai t hitung

$>$ t tabel $(4,736>1,989)$ dan signifikansi $<0,05(0,000<0,05)$ maka Ho ditolak.

\section{HASIL KOEFISIEN DETERMINASI}

\begin{tabular}{|c|c|c|c|c|}
\hline Model & $\mathrm{R}$ & R Square & Adjusted R Square & Std. Error of the Estimate \\
\hline 1 &, $838^{\mathrm{a}}$ &, 702 &, 691 & 1,73748 \\
\hline
\end{tabular}

a. Nilai R2 sebesar 0,702 artinya persentase sumbangan pengaruh variabel Pengalaman Kerja, Motivasi Kerja, dan Gaya Kepemimpinan terhadap Kinerja Karyawan sebesar 
$70,2 \%$, sedangkan sisanya sebesar $29,8 \%$ dipengaruhi oleh variabel lain yang tidak dimasukkan dalam model ini.

b. Adjusted R Square, yaitu R Square yang telah disesuaikan, nilai sebesar 0,691; ini juga menunjukkan sumbangan pengaruh variabel independen terhadap variabel dependen.

\section{KESIMPULAN DAN SARAN}

Berdasarkan hasil penelitian maka dapat disimpulkan bahwa:

a. Persentase sumbangan pengaruh variabel independen terhadap Kinerja Karyawan sebesar 70,2\%, sedangkan sisanya sebesar $29,8 \%$ dipengaruhi oleh variabel lain yang tidak dimasukkan dalam model ini.

b. Pengalaman Kerja berpengaruh secara parsial terhadap Kinerja Karyawan. Pengaruh dari Pengalaman Kerja dalam penelitian ini merupakan pengaruh paling besar sumbangsinya dibandingkan dua varibael independen lainnya.

c. Motivasi Kerja berpengaruh secara parsial terhadap Kinerja Karyawan. Pengaruh dari Motivasi Kerja dalam penelitian ini sangat signifikan setelah Pengalaman Kerja dan Gaya Kepemimpinan.

d. Gaya Kepemimpinan berpengaruh secara parsial terhadap Kinerja Karyawan. Berpengaruhnya Gaya Kepemimpinan memiliki pengaruh yang besar setelah Pengalaman Kerja.

Berdasarkan hasil penelitian yang telah dilakukan maka diajukan saran, antara lain:

Untuk kepentingan manajemen PT ELKAU agar dapat meningkatkan lagi kualitas sumber daya manusia yang lebih baik dengan berbagai cara, antara lain:

1. Menyediakan bantuan dan dukungan yang lebih baik lagi terutama bagi karyawan yang mengalami kendala dalam sistem kerja baik dari sarana dan prasarana, sistem GPS yang memadai.

2. Meningkatkan pelatihan secara berlaka kepada karyawan agar memahami sistem GPS dan sebagainya.

\section{DAFTAR KEPUSTAKAAN}

Anthony, Robert N \& Govindarajan, Vijay. (2013). Sistem Pengendalian Manajemen (ed 11.). Jakarta : Salemba Empat.

George, R, Terry, Leslie W. Rue. (2003). Dasar-Dasar Manejemen. Jakarta: PT. Bumi Aksara. Narbuko, Cholid dan Abu Achmadi. (2010). Metodologi Penelitian. Jakarta : Bumi Aksara.

Noe, Raymond A., Hollenbeck, John R., Gerhart, Barry., \& Wright, Patrick M. (2014). Fundamentals of Human Resource Management ( $5^{\text {th }}$ ed.). Singapore : McGraw-Hill.

Priyatno, Duwi. (2014). SPSS 22 Pengolah Data Terpraktis. Yogyakarta : Andi.

Robbins, Stephen P \& Judge, Timothy A. (2009). Organizational Behavior (13 ${ }^{\text {rd }}$ ed.). USA : Pearsons Prentice Hall.

Sarjono, Haryadi dan Winda Julianita. (2011). SPSS vs LISREL: Sebuah pengatar, Apliaksi Untuk Riset. Jakarta : Salemba Empat.

Sekaran, Uma. (2011). Metodologi Penelitian Untuk Bisnis. Jakarta : Salemba Empat.

Sidonews.com. (2016). Banjir Elektronik China Penyebab Pabrik Toshiba Tutup. Retrieved Febuary 4, 2016, from Sidonews Website https://ekbis.sindonews.com.

Springer, Gary Jon. (2011). A Study of Job Motivation, Satisfaction, and Performance among Bank Employees. Spring - Journal of Global Business Issues, 5 (1), 29-42. 